\title{
OBJECT ORIENTED OIL SPILL CONTAMINATION MAPPING IN WEST SIBERIA WITH QUICKBIRD DATA
}

\author{
S. Hese *, C. Schmullius \\ Friedrich-Schiller University Jena, Institute of Geography, Department of Earth Observation, Löbdergraben 32, 07743 Jena, \\ Soeren.hese@uni-jena.de
}

KEY WORDS: Oil Spill, Quickbird, Object Oriented, Context Classification, Siberia

\begin{abstract}
:
This paper presents concepts for an object based mapping and classification system for terrestrial oil spill pollutions in West-Siberia using Quickbird data. The work presented is part of the OSCaR pilot study (Oil Spill Contamination and mApping in Russia) and is co-financed by the Federal Ministry of Education and Research (BMBF) Germany as part of the Core-to-Core activities on "The Symptoms of Environmental Change in the Siberian Permafrost Region" with the Japan Society of the Promotion of Science (JSPS). An object oriented classification system is created to map contaminated soils and vegetation using spectral information, shape and context information. Additionally time series analysis will be performed with multitemporal Landsat data for a 15 year time-frame for mapping of larger patches of contaminated land surfaces in the second phase of OSCaR. Validation of the results is planned to be done with field data from the Russian partners at the Yugra State University in Khanty-Mansiyskiy. Detailed information about age and position of the polluted areas is used for this analysis.
\end{abstract}

\section{INTRODUCTION}

Research on the application of Earth observation data and image processing methods for oil spills concentrated in the past on marine pollution scenarios. For marine and coastal applications various results and methods have been published using SAR data to monitor extend, type and drift of oil pollutions (Pedersen et al. 1996, Wismann et al. 1998, Espedal \& Wahl 1999, Jones 2001, Fiscella et al. 2000, Lu 2003, Brekke $\&$ Solberg 2005). Terrestrial oil spill pollutions did not receive very much attention. This is due to the regional and small scale character of terrestrial oil spill contaminations often also complicated by mixed spectral signatures with the signal of recovering vegetation, dead vegetation and the signal from soils. Hörig et al. (2001) analysed the spectral properties of oil contaminated soils and sands using hyperspectral Hymap data and found specific absorption bands in the SWIR region of the spectrum. Salem and Kafatos (2005) investigated the potential of spectral linear unmixing for delineating different oil contamination types in AVIRIS hyperspectral data.

With increasing demand on the global markets for crude oil it can be expected that the environmental impact for areas with intensive production of oil and gas will become a major issue in the near future. Earth observation can deliver precise information about the state and changes of the ecosystem in these regions.

For the detection of hydrocarbons hyperspectral data has been reported to be very useful. The only system with appropriate geometrical resolution at the time of writing is the Hyperion system with 30 meters spatial resolution and 220 bands with 10 $\mathrm{nm}$ band width (Folkman et al. 2000). Calibration of this data is however problematic as the spectral ground measurements in West-Siberia are not easily obtainable. Data with very high spatial resolution is available and covers the visible and near infrared domain of the spectrum with 0.6 to $2.5 \mathrm{~m}$ spatial resolution. For the analysis of terrestrial oil contamination and the detection of specific materials a combination of both data types would be desirable to determine the mixed pixel content of the hyperspectral signal.

The presented work of the OSCaR project concentrates on spatial high resolution data in combination with time series analysis to detect contaminations and to precisely date the oil spill events. The methods utilised concentrate on object oriented image processing techniques and time series analysis. The Khanty-Mansiyskiy area in West Siberia is one of the most important territories for the Russian oil and gas production with $58 \%$ of the total Russian oil production and being on the $3^{\text {rd }}$ place with its national gas production. Large areas are oil and waste water polluted from pipeline leakages with heavy direct impact on underground and surface water quality, ecological conditions and quality of living (Figure 1). The region is largely covered by taiga and tundra forest with subarctic to continental climate and areas of permafrost with annual precipitation between 400 to $500 \mathrm{~mm}$. The area has low nutrient peat based soils with long biological recovery times and includes important habitats for endangered fauna. Due to low evaporation and low temperatures, lack of drainage and small infiltrations rates large wetlands are formed. Thermokarst occurs due to melting ground ice (Pattern Ground) and thaw lakes and thermokarst pits can occur. The geological structure of the West Siberian basin is dominated by lower cretaceous and jurassic sections. The oil and gas resources are found in stratigraphic and structural traps that extend into the Kara Sea region.

Population is concentrated in a number of urban and industrial areas, which have developed over the last half century due to a strong immigration. The region has compared with the Russian average low health rates often related to the environmental quality of living with a potential (suspected) relationship with a "higher than average" (IWACO 2001) level of diseases. The number of indigenous people of West Siberia based on

\footnotetext{
* Corresponding author.
} 
traditional family structured hunting, reindeer herding, fishing and nomadic lifestyle (Khants, Mansis, Nenets) has been severely reduced since the 1950s (IWACO Report 2001). The Russian Federation belongs to the top 5 energy producers with Germany and other European countries being the major importers. West Siberia is the oldest oil and gas region mainly exploited by Russian privatised companies (LUKoil, Surneftegaz, Yukos, Sidanko, Tatneft, Tyumen Oil (TNK)). According to the IWACO Report the privatisation has transferred the responsibility for past and current environmental impacts from the government to the oil companies exploiting the fields. The governmental authorities remain however responsible for monitoring and enforcement of environmental legislation and developing strategies for the energy sector. The IWACO Report states that about 700000 to 840000 hectares in West Siberia are oil polluted - a much larger area than indicated by the government or oil company statistics.

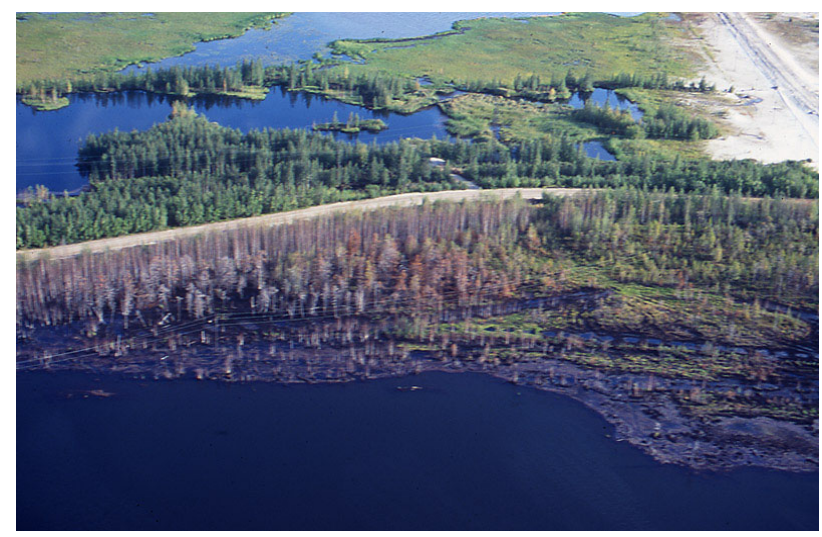

Figure 1. Oil spill polluted forest area in the Samotlor oil field, West Siberia (S. Cejchan, BFH Hamburg).

The major environmental and social impacts come from activities like:

1. pipeline breaks, spills, and pipeline accident,

2. deposition of oily muds, drilling and production wastes,

3. chemical waste disposal and leaking storages,

4. surface water pollution in water bodies around oil fields,

5. emissions of hydrocarbons and greenhouse gases from flaring and venting of gases and oily waste burning and

6. inadequate emergency planning and under-developed awareness of environmental impact and remediation measures.

In the Khanty Mansiysk district more than 62000 oil wells have been drilled and according to sources from the IWACO report $64000 \mathrm{~km}$ of pipelines have been constructed.

The magnitude of the oils spills is very difficult to calculate. Accurate data on numbers is very hard to obtain. According to different sources about $2 \%$ of the total oil quantity produced is spilled into the tundra. The average oil spill loses about 2 tons of oil and covers about $1000 \mathrm{sqm}$.

\section{THE OSCAR PILOT STUDY (OIL SPILL CONTAMINATION MAPPPING IN $\underline{\text { RUSSIA) }}$}

The OSCaR (OilSpill Contamination mapping in Russia) pilot study project was initiated in 2005 as part of BMBF financed permafrost degradation proposal preparation meetings in Russia (Challenges of Permafrost Degradation of Siberian Soils to Science and Technology) and Core2Core activities with the Japanese JSPS programme in 2005.
The German Ministry for Education and Science co-financed OSCaR with funding for Earth observation data of the Khanty Mansiysk area (Landsat and Quickbird data). The main goal of OSCaR is to test very high resolution multispectral data for oil spill contamination mapping with advanced image processing algorithms. The methodological focus is on spatial high resolution data analysis. Object oriented image analysis has been carried out to link the spectral characteristics of oil spill objects to secondary image object features that have a contextual relation to oil spills (infrastructure, drilling platforms, pipelines, waste water reservoirs or drilling mud reservoirs). Post classification analysis of specific objects has to be performed to identify the structural identity of oil spills and the related objects.

In a second stage the development of the region is analysed using multi temporal data with lower spatial but with very high temporal resolution. Changes will be mapped starting in the early 80 s and with $2-3$ year steps until 2005 . The main interests are 1 . to identify area and position of larger oil spills and 2. to map changes in industrial structures and infrastructure (increase of oil wells, construction of new pipelines etc.) Identification of oil spills in multitemporal data is important for dating of spill events and large oil pipeline leakages.

\section{DATA}

For the OSCaR project very high resolution Quickbird data was selected covering an approximate $20 \times 16 \mathrm{~km}$ subset of a region in the Khanty Mansiysk area north of Surgut in West Siberia. A full "Basic Set" Quickbird data take was ordered from the archive from 2004 (acquisition date 2004-09-27) including the full resolution multispectral information $(2.72 \mathrm{~m})$ and a panchromatic data layer with 0.68 meter spatial resolution (Table 1). The data was imported and georeferenced using the RPCs provided by Digital Globe without ortho correction.

\begin{tabular}{|c|c|}
\hline $\begin{array}{c}\text { Quickbird } \\
\text { data }\end{array}$ & Digital Globe \\
\hline Date & 20040927 \\
\hline Cloud Cover & $1 \%$ \\
\hline Catalog ID & $101001000348 \mathrm{E} 202$ \\
\hline Resolution & $0.68 / 2.72$ meters \\
\hline Off-Nadir & 19 degrees \\
\hline
\end{tabular}

Table 1. Quickbird data

The data was interpolated to the appropriate resolution with a bilinear interpolation to UTM 43 (WGS84) in 16 Bit radiometric resolution (NN interpolation was not performed as no pixel based analysis is planned and smooth object geometry is priority).

Landsat ETM+ and Landsat TM5 data was ordered for the path/row sets $156 / 17$ and $157 / 17$ with a temporal coverage for the years 1987, 1988, 1990, 1995, 2000, 2001 and 2003. Ground information was provided by the Russian partners from the Yugra State University in Khanty-Mansiyskiy. Digital maps with indicated dates and extend of oil spill events and digitized information about infrastructure and the position of oil wells. 


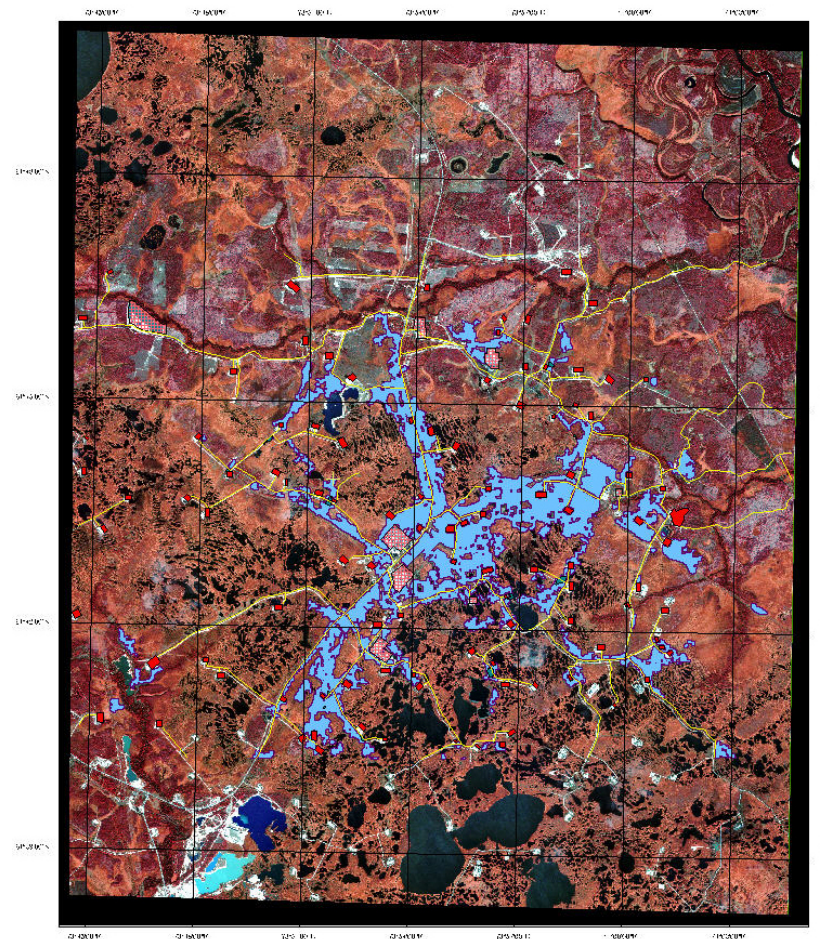

Figure 2. Quickbird data set from 27. September 2004, overlay with oil contaminated ground truth information layer, infrastructure layer with positions of oil wells (Kusts) and pipelines, RGB with Quickbird channels 4-3-2.

\section{METHODS}

The object-based strategy for data classification (Baatz and Schäpe 1999 and Benz et al. 2004) uses as a first stage a segmentation into different scales of image object primitives according to spatial and spectral features. The segmentation is a bottom up region merging technique starting with one pixel sized objects. In numerous subsequent steps smaller objects are merged into bigger objects (pair wise clustering) minimizing the weighted heterogeneity of resulting objects using the size and a parameter of heterogeneity (local optimization procedure) (Benz et al. 2004). This concept has the advantage to account for contextual information using image objects instead of the pixel based concept used frequently as the basic element in Earth observation image analysis. In a second stage rule-based decisions can be used to classify the multi scale image objects. Class based feature definitions (integrating a post classification analysis) are possible as well as the inheritance of class descriptions to form a class hierarchy. Image processing tasks can be performed using vector shape and vector characteristics. This increases the flexibility of the image processing concept and integrates GIS-like data queries in an attribute database directly into the image processing and analysis approach. New attributes (like object shape or structural characteristics, e.g. distance to other objects) can be used.

Object based image analysis has been used since 1999 for different approaches and in different remote sensing disciplines. Various approaches applied object oriented methods to urban applications (Damm et al. 2005; Grenzdörfer 2005, Argialas \& Derzekos 2003), biotope classification (Leser 2002) and forest applications: Mitri and Gitas (2002) developed an object oriented classification model for burned area mapping. Flanders et al. (2003) tested the object oriented approach for forest cut block delineation. Hese et al. (2005) used contextual information to classify forest cover change patterns and Chubey et al. (2006) analyzed object oriented procedures for forest inventory parameters from Ikonos data. Arroyo et al. (2005) tested object oriented methods for regional fuel mapping with Quickbird data.

Advantages over pixel-based approaches have been published mainly using very high resolution airborne or orbital Earth observation data. The primary advantage of reducing the spectral variability in very high spatial resolution data sets (spatial resolution better $5 \mathrm{~m}$ ) is however only one aspect of object oriented image analysis.

In this work object oriented image analysis has been carried out to link the spectral characteristics of oil spill objects to secondary image object features that have a contextual relation to oil spills (e.g. infrastructure objects, oil well objects, pipeline objects and waste water reservoir objects or drilling mud reservoir objects). The classification of these secondary objects is done in different segmentation scales. Post classification analysis of specific objects has to be performed to identify the structural identity of oil spills and related objects.

The dataset is segmented into three different layers with segments scales.

A hierarchical class description is build that classifies water bodies and vegetation cover types in the finest level and infrastructure, roads and industrial sites in the coarser segmentation levels. Road objects and industrial classes are differentiated with object shape features and with spectral characteristics. Oil contaminated areas are mapped with a thresholding of NDVI calculations into four different vegetation sub classes ranging from healthy vegetation to heavily polluted vegetation. The correlation between NDVI and oil spills is based on the reduced amount of healthy vegetation on oil contaminated soils. This is clearly visible in the NIR with a reduced amount of reflectance in polluted areas. Water bodies and non-vegetated areas have been masked out to avoid the overlap with non-vegetated areas through inverted expressions (Figure 3).

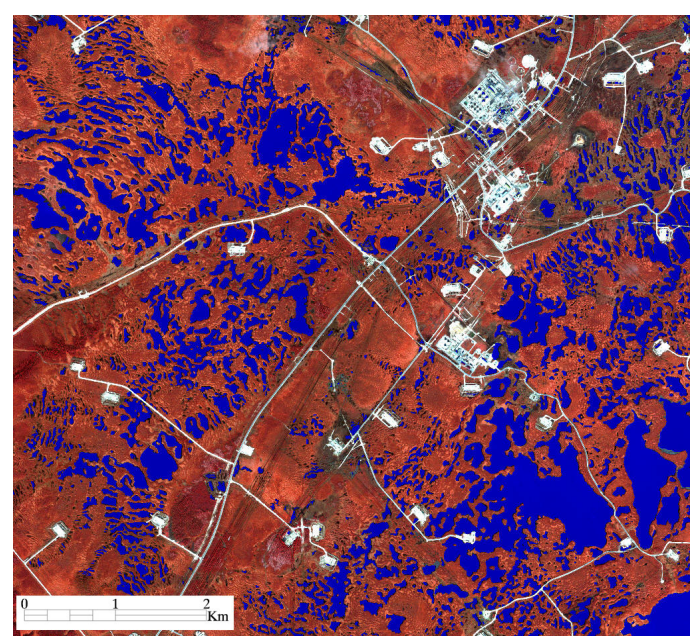

Figure 3. Masked water bodies using spectral signatures. Water bodies are used as a mask for the classification of other classes through the application of an inverted expression. 


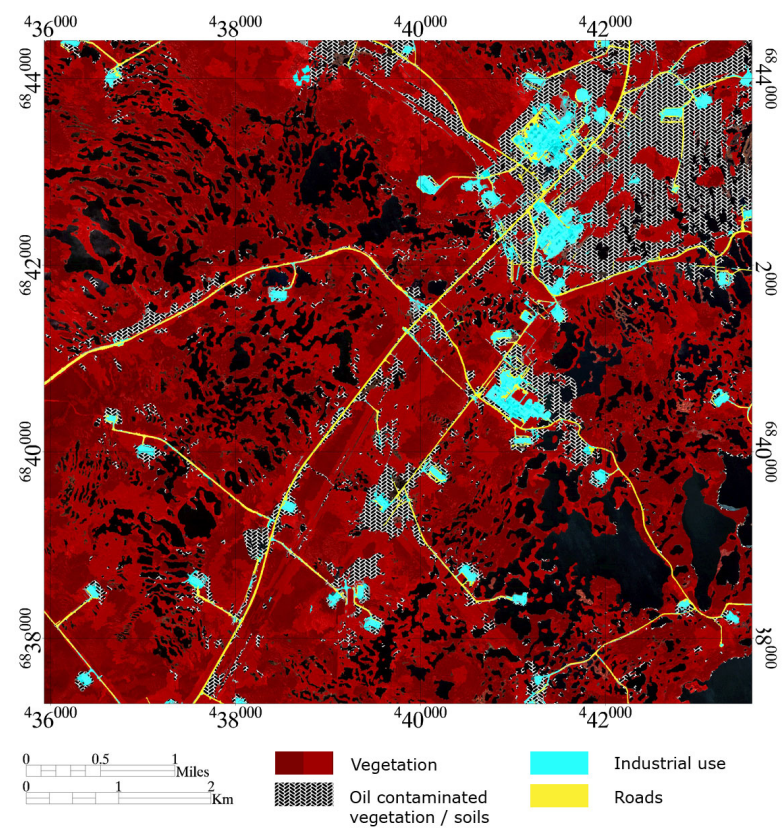

Figure 4. Results of an object based classification of oil contaminated surfaces using object shape, spectral information and object context information (class related features). Data used: Quickbird multispectral data with 2.5 meter resolution. The distance to road objects and to industrial objects was used to increase the classification accuracy of oil spill contaminated surface types. Water bodies were masked out in this analysis.

To increase the accuracy of the classification class related feature sets are designed that introduce distance in relation to the class infrastructure and industrial area as a characteristic object property of oil spill objects. Oil polluted areas therefore are only classified in a defined distance (buffer) to road networks, oil production platforms or other industrial areas (Figure 4 and class description shown in Figure 6).

A typical example of oil polluted vegetation in direct neighbourhood of oil wells is shown in Figure 5.

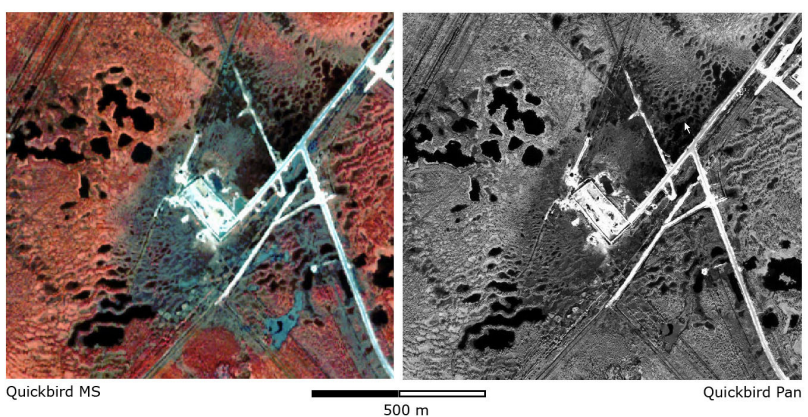

Figure 5. Quickbird multispectral (2.5 m, RGB 4-3-2) and panchromatic $(0.6 \mathrm{~m})$ data subsets of an oil spill area connected to a drilling platform area and infrastructure image objects (West Siberia, Khanty Mansiysk district).

In a second stage in OSCaR the regional changes will be analysed using multi temporal data with lower spatial resolution but with high temporal resolution. The changes will be mapped starting in the early 80 s and with $2-3$ year steps until 2004 . The main interests are 1. mapping of changes in industrial object structures and infrastructure (increase of oil wells, construction of new pipelines etc.) and 2. dating and identification of areas with large oil spills.

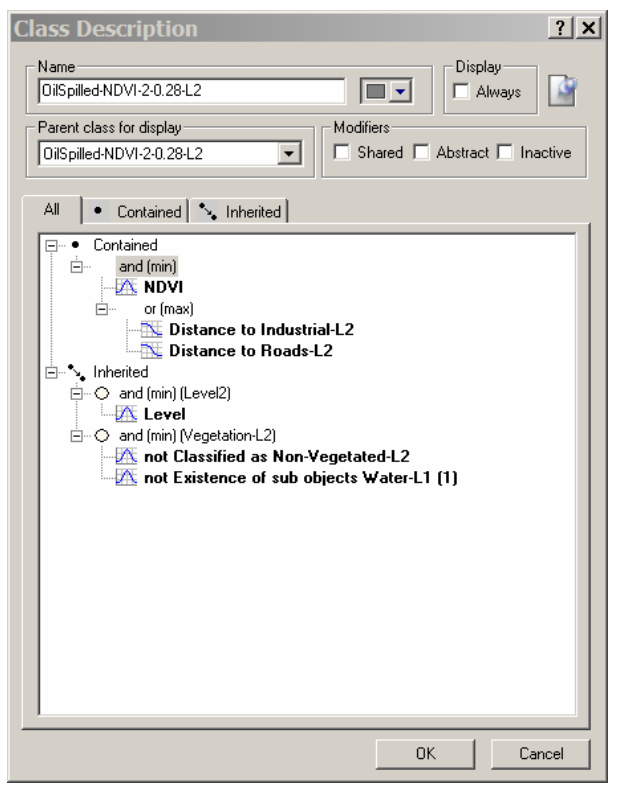

Figure 6. Class description for oil contaminated surface types using NDVI thresholds and class related distance functions to industrial objects and road objects.

\section{RESULTS}

For this study using a small subset of the available Quickbird data a high percentage (more than $10 \%$ ) of the area was found to be oil spill contaminated. Of the 25856 ha of the subset about 1298 are occupied by industrial objects, 3120 ha are oil spilled and 6166 ha are open water bodies. The amount of water areas indicates that also water bodies are probably affected by oil spill pollutions. The detection of water oil spills has been neglected in this work. The developed class hierarchy will be refined and applied to the complete dataset.

\section{SUMMARY}

This paper presents first results of the OSCaR pilot study for terrestrial oil spill classification with very high resolution Earth observation data and object oriented image processing methods. The developed class hierarchy for a test area in the Khanty Mansiysk district classified oil spills using spectral information, object shape information and class related features. Final accuracy assessment has not been performed for this study yet but the preliminary results show that class related information can be applied successfully to utilise the structural image object information.

\section{REFERENCES}

Arroyo, L., Healey, S., Cohen, W., Cocero, D., Manzanera, J.A., 2005. Regional fuel mapping using an object-oriented Classification of Quickbird imagery. In: Proceedings of NARGIS 2005 - applications in tropical spatial science. 4th 7th July 2005, Charles Darwin University, Darwin, NT, Australia.

Argialas. D., p. Derzekos, 2003. Mapping urban green from IKONOS data by an object-oriented knowledge-base and fuzzy logic . In: Proc. SPIE Vol. 4886, p. 96-106, Remote Sensing for 
Environmental Monitoring, GIS Applications, and Geology II; Manfred Ehlers; Ed. 22-27 September, Aghia Pelagia, Crete.

Baatz, M., A. Schäpe, 1999. Object-oriented and multi-scale image analysis in semantic networks, in: proceedings of the $2^{\text {nd }}$ International Symposium: Operationalization of Remote Sensing, 16-20 August, ITC, NL.

Benz, U.C., P. Hofmann, G. Willhauck, I. Langenfelder, M. Heynen, 2004. Multi-resolution, object-oriented fuzzy analysis of remote sensing data for GIS-ready information, ISPRS Journal of Photogrammetry and Remote Sensing, 58 (2004), 239-258.

Brekke, C., Solberg, A.H.S., 2005. Review: Oil spill detection by satellite remote sensing, Remote Sensing of Environment, No 95, 2005, pp. 1-13.

Chubey, M., S. Franklin and M. Wulder, 2006. Object-based Analysis of Ikonos-2 Imagery for Extraction of Forest Inventory Parameters. $P E \& R S$, April 2006.

Damm, A., P. Hostert, S. Schiefer, 2005. Investigating Urban Railway Corridors with Geometric High Resolution Satellite Data, Urban Remote Sensing 2005, Berlin Adlershof.

Espedal, H.A., Wahl, T., 1999. Satellite SAR oil spill detection using wind history information, Int. J. Remote Sensing, 1999, Vol. 20, No. 1, pp. 49-65.

Fiscella, B., Giancaspro, A., Nirchio, F., Pavese, P., Trivero, P., 2000. Oil Spill Detection using marine SAR images. Int. J. Remote Sensing, 2000, Vol. 21, No. 18, pp. 3561-3566.

Flanders, D., M. Hall-beyer \& J. Pereverzoff, 2003. Preliminary evaluation of eCognition object-based software for cut block delineation and feature extraction. In: Canadian Journal of Remote Sensing, Vol. 29, No. 4, pp. 441-452, August 2003.

Folkman, M., J. Pearlman, L. Liao, P. Jarecke, 2000. EO-1 Hyperion hyperspectral imager design, development, characterization, and calibration, SPIE, Vol. 4151, 2000.

Hese, S., Schmullius, C., 2005. Forest Cover Change in Siberia - Results from the Siberia-II Project, International Conference on Remote Sensing of Environment, Conference Proceedings, St. Petersburg, Russia.

Hörig, B., Kühn, F., Oschütz, F., Lehmann, F., 2001. HyMap hyperspectral remote sensing to detect hydrocarbons, Int. J. Remote Sensing, 2001, Vol. 22, No. 8, pp. 1413-1422.
IWACO Report, 2001. West Siberia Oil Industry Environmental and Social Profile, Final Report, edited by M. Lodewijkx, V. Ingram, R. Willemse, June 2001.

Jones, B., 2001. A comparison of visual observations of surface oil with Synthetic Aperture Radar imagery of the Sea Empress oil spill, Int. J. Remote Sensing, 2001, Vol. 22, No. 9, pp. 16191638.

Salem, F., Kafatos, M., El-Ghazawi, T., Gomes, R., Yang, R., 2005. Hyperspectral Image Assessment of oil-contaminated wetland, Intern. Journal of Remote Sensing, Vol. 26, No. 4, 20 February 2005, 811-821.

Leser, C., 2002. Operationelle Biotoptypenkartierung mit HRSC-Daten - Probleme und Lösungsansätze. In: Blaschke, T. (Hrsg.): GIS und Fernerkundung: Neue Sensoren - Innovative Methoden. Wichmann Verlag, Heidelberg: 88-97.

Lu, J., 2003. Marine oil spill detection , statistics and mapping with ERS SAR imagery in south-east Asia, Int. J. Remote Sensing, 2003, Vol. 24, No. 15, pp. 3013-3032.

Mitri, G.H. \& I. Gitas, 2002. The development of an objectoriented classification model for operational burned area mapping on the Mediterranean island of Thasos using LANDSAT TM images, in Viegas X. (ed.) Forest Fire Research \& Wildland Fire Safety, 2002 Millpress, Rotterdam, ISBN 9077017-72-0.

Pedersen, J.P., Seljev, L.G., Srom, G.D., Follum, O.A., Andersen, J.H., Wahl, T. and Skolev, A., 1995. Oil spill detection by use of ERS SAR data-from R\&D towards preoperational early warning detection service. Proceedings of the 2nd ERS Applications Workshop, L ondon, 6-8 December 1995, pp. 181-185.

Salem, F., Kafatos, M., El-Ghazawi,T., Gomes,R., Yang, R., 2005. Hyperspectral image assessment of oil-contaminated wetland, Int. J. Remote Sensing, Vol. 26, No.4, 20 February 2005, pp. 811-821.

Wismann, V., Gade, M., Alpers, W., Hühnerfuss, H., 1998. Radar signatures of marine mineral oil spills measured by an airborne multi frequency radar, Int. J. Remote Sensing, 1998, Vol. 19, No. 18, pp. 3607-3623. 